\title{
Coil Optimization for High Temperature Superconductor Machines
}

Mijatovic, Nenad; Jensen, Bogi Bech; Abrahamsen, Asger Bech; Rodriguez Zermeno, Victor Manuel; Træholt, Chresten; Pedersen, Niels Falsig

Published in:

IEEE Transactions on Applied Superconductivity

Link to article, DOI:

10.1109/TASC.2010.2094171

Publication date:

2011

Document Version

Publisher's PDF, also known as Version of record

Link back to DTU Orbit

Citation $(A P A)$ :

Mijatovic, N., Jensen, B. B., Abrahamsen, A. B., Rodriguez Zermeno, V. M., Træholt, C., \& Pedersen, N. F. (2011). Coil Optimization for High Temperature Superconductor Machines. IEEE Transactions on Applied Superconductivity, 21(3), 1136-1140. https://doi.org/10.1109/TASC.2010.2094171

\section{General rights}

Copyright and moral rights for the publications made accessible in the public portal are retained by the authors and/or other copyright owners and it is a condition of accessing publications that users recognise and abide by the legal requirements associated with these rights.

- Users may download and print one copy of any publication from the public portal for the purpose of private study or research.

- You may not further distribute the material or use it for any profit-making activity or commercial gain

- You may freely distribute the URL identifying the publication in the public portal 


\title{
Coil Optimization for High Temperature Superconductor Machines
}

\author{
N. Mijatovic, Student Member, IEEE, B. B. Jensen, Member, IEEE, A. B. Abrahamsen, V. M. R. Zermeno, \\ C. Træholt, and N. F. Pedersen
}

\begin{abstract}
This paper presents topology optimization of HTS racetrack coils for large HTS synchronous machines. The topology optimization is used to acquire optimal coil designs for the excitation system of 3 T HTS machines. Several tapes are evaluated and the optimization results are discussed.

The optimization algorithm is formulated to minimize the cost for the coils wound with one type of HTS as well as multiple HTS types. It could also be used to minimize other parameters, e.g. space required for the coils. The results are inherently highly dependent on the HTS properties, which at $20 \mathrm{~K}$ seem to be in favor of the $1 \mathrm{G}$ tape. The maximal HTS savings achieved allowing multiple current supplies in the excitation system are investigated and estimated to be in the range of $50 \%$ for highly nonlinear J-B dependence HTS tapes.
\end{abstract}

Index Terms-HTS coil optimization, HTS machines, topology optimization.

\section{INTRODUCTION}

$\mathbf{H}$ IGH temperature superconducting (HTS) applications are currently limited to a few main areas, such as advance medical diagnostics tools (MRI and NMR) and high energy particle research (accelerators). Large scale HTS applications have been thoroughly demonstrated in the energy sector, e.g. HTS cables, Superconducting Magnetic Energy Storage and HTS machines. Yet their commercialization is still limited by the cost of the HTS materials.

Optimization of the superconducting devices is crucial in order to make them competitive in a free market. At present the two main HTS candidates suitable for industrial applications are first generation $(1 \mathrm{G}) \mathrm{BSCCO}$ and second generation $(2 \mathrm{G})$ Coated Conductors. The price and performance of the HTS conductors depend strongly on the type of HTS material including: magnetic field dependent critical current density $J_{c}(B)$, manufacturing procedures, availability and quantity.

Manuscript received August 03, 2010; accepted November 14, 2010. This work was supported in part by the Technical University of Denmark under the globalization funded Project Superwind.dk.

N. Mijatovic, B. B. Jensen, N. F. Pedersen, and C. Træholt are with the Department of Electrical Engineering, Technical University of Denmark, Lyngby DK-2800, Denmark (e-mail: nm@elektro.dtu.dk; bbj@elektro.dtu.dk; nfp@elektro.dtu.dk; ctr@elektro.dtu.dk).

A. B. Abrahamsen is with the Materials Research Division, Risø National Laboratory for Sustainable Energy, Technical University of Denmark, Roskilde DK-4000, Denmark (e-mail: asab@ risoe.dtu.dk).

V. M. R. Zermeno is with the Department of Mathematics, Technical University of Denmark, Lyngby DK-2800, Denmark (e-mail: V.Zermeno@mat.dtu. $\mathrm{dk})$.

Color versions of one or more of the figures in this paper are available online at http://ieeexplore.ieee.org.

Digital Object Identifier 10.1109/TASC.2010.2094171
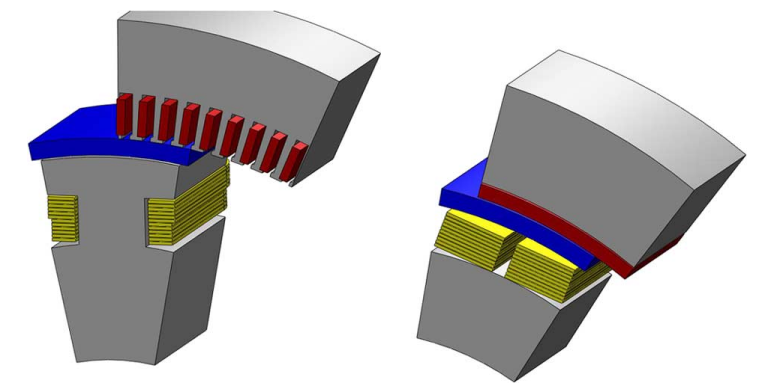

Fig. 1. Conceptual design of one pole-section for salient (left) and non-salient (right) synchronous machines with conventional and air-gap armature windings respectively. The magnetic steel is gray, the armature winding is dark red, the thermal insulation (vacuum chamber, spacers, radiation shield) is blue, and the space for the HTS coils is yellow.

The HTS price is usually the dominating factor of any system employing HTS. Optimization of the HTS usage and cost is therefore one of the main tasks of any superconducting system's designer. In the case of the electrical machines, many designs have been optimized for different applications ranging from air industry to utility companies [1]-[3].

We have employed the constrained Finite Element topology optimization in order to obtain improved HTS coil designs. Doing so it is possible to minimize the amount of HTS needed and hence the cost of HTS, or even to pinpoint a combination of HTS tapes with different properties in order to minimize the cost of the HTS machine.

\section{Methodology}

First the model of the HTS machine will be discussed, in order to formulate the topology optimization problem for the HTS coils in a machine. After that, details of the design of the HTS coils, HTS tapes, and most important constraints for the HTS coils will be reviewed. Finally, the formulation, implementation, and results of the topology optimization are described.

\section{A. HTS Machine Design}

Recommended HTS machine designs vary depending on the application that the machine is intended for. The common characteristic for all HTS machines, and one of their main benefits, is the power density which could be significantly larger than in conventional machines [4].

The two main designs, which the HTS synchronous machines are gravitating towards, are salient pole machines with conventional armature windings and non-salient multi-pole machines with air-gap armature windings [4], [5]. Both designs are shown and described in the Fig. 1. 
The magnetic field is established by the HTS excitation winding. A cryostat for thermal insulation between the armature windings at room temperature and the HTS excitation windings at cryogenic temperatures is necessary. Given that the radial thickness of the cryostat is crucial for the machine design and directly responsible for the increase in required MMF, it is important to have a good estimate of the cryostat thickness necessary for operational temperatures between $20 \mathrm{~K}$ and $80 \mathrm{~K}$.

The choice of material for the cryostat could be stainless steel (SS) or composite materials. The advantage of SS is the ease of manufacturing, and the advantage of the composite material is zero eddy current losses. The conduction and radiation heat transfer need to be suppressed with a vacuum chamber and multilayer insulation (MLI). The heat transfer through the mechanical and electrical connections also needs to be minimized. It could be assumed that for temperatures above $60 \mathrm{~K}$ a cryostat thickness of $20 \mathrm{~mm}$ can be achieved and for temperatures between $20 \mathrm{~K}$ and $60 \mathrm{~K}$ a cryostat thickness of $50 \mathrm{~mm}$ is necessary, due to the additional MLI and tighter heat inflow restriction because of lower cooling efficiency at lower temperatures.

Armature designs for HTS machines have been and still are a topic of a debate. Some arguments in favor of the air-gap armature design are removal of teeth saturation and higher armature current loadings. The advantages of air-gap armature windings have not yet been proven commercially and it was reported [6] that the air-gap armature winding involves several challenges, which still needed to be addressed e.g. cooling, mechanical integrity, assembly, and eddy current loss. However, if the trend for development of the compact machines continues, the air-gap armature winding's inherent advantages over conventional slotted armature windings will make the air-gap armature a more favorable choice.

It is also possible to draw some electromagnetic parallels between air-gap and conventional armature windings in slots. Having slotted configuration windings allows very small electromagnetic air gaps, but it also effectively decreases the radial flux path surface of the armature steel. This is taken in to account in conventional analytical machine design by the Carter coefficient, which modifies the effective air-gap to account for the effects of the iron teeth and slots dimensions. Bearing this in mind the model in Fig. 2 can also be used to analyse conventional slotted armatures by altering the inner radius of the stator steel according to the Carter coefficient.

\section{B. HTS Coil Design}

HTS tapes, both $1 \mathrm{G}$ and $2 \mathrm{G}$, are manufactured as a thin tapes $(0.1 \mathrm{~mm}-0.4 \mathrm{~mm}$ ) of different widths (where $5 \mathrm{~mm}$ is the most common) [7]-[9]. In order to estimate the impact of very high engineering current densities in the HTS 2 G tapes, it is assumed that coated insulation is applied. This yields cross sectional areas of only $1 \mathrm{~mm}^{2}$ for insulated tapes which allows compact coil designs. This tape would correspond to the most expensive tape and it is currently available in limited lengths. Extended tape lengths are currently only available for the $1 \mathrm{G}$ tapes, which adds additional constrains on large scale applications.

Due to the mechanical limitations, the preferred coil layout for the HTS tapes is racetrack coils. Commercially available HTS tape can also be purchased in insulated form (usually

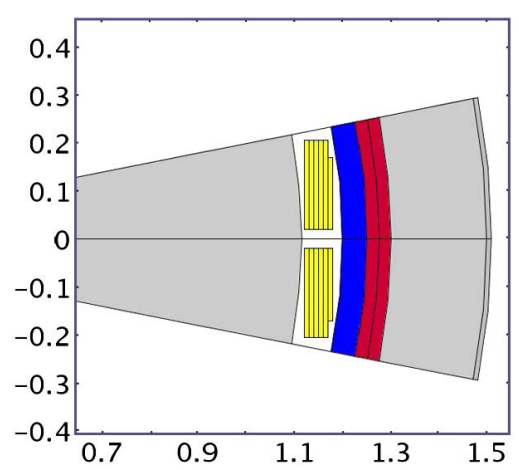

Fig. 2. Simplified model of a synchronous HTS machine with air-gap winding. The magnetic steel is gray, armature winding is dark red, thermal insulation (vacuum chamber, spacers, radiation shields) is blue and space for HTS coils is yellow. The units of $x$ and $y$ axes are $[\mathrm{m}]$.

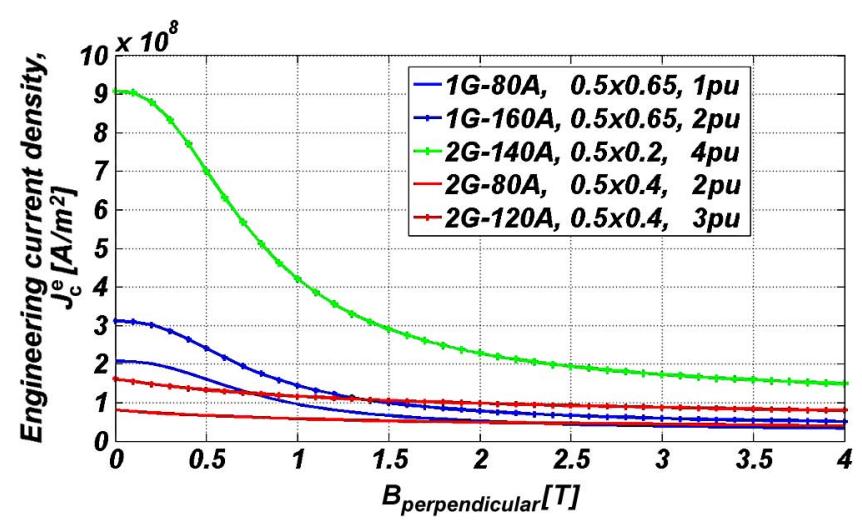

Fig. 3. Estimated engineering current density for $1 \mathrm{G}$ and $2 \mathrm{G}$ tapes at $20 \mathrm{~K}$. The legend shows the HTS type, the critical current at $77 \mathrm{~K}$ in the self field, the estimated dimensions of the cross section of the insulated HTS tapes in [mm], and the estimated price of the tape all normalized to the price of $1 \mathrm{G}-80 \mathrm{~A}$. The insulation of the tapes is assumed to be $0.3 \mathrm{~mm}$ for glass fiber and $0.15 \mathrm{~mm}$ for coated insulation.

Kapton of Glass-Fiber tape insulated) or the tape could be insulated by the coil manufacture. The insulation of the HTS tape can have large impacts on the compactness of the HTS structures.

The HTS' magnetic dependence of its engineering critical current, i.e. $J_{c}^{e}-B$ data, is not standardized and is highly dependent on several parameters. In order to compare different types of HTS tapes, the data from published material [6]-[9] is used in this study together with estimated price ratios for the HTS tapes, Fig. 3.

It is also assumed that the price of the same type of HTS tapes scales linearly with the current rating. All HTS prices are normalized to $1 \mathrm{G}-80 \mathrm{~A}$, hence having the $1 \mathrm{G}-80 \mathrm{~A}$ BSCCO tapes as a base value. The HTS $2 \mathrm{G}$ tapes are more expensive at present but it is predicted that they could become cheaper than $1 \mathrm{G}$ tapes.

\section{Machine Electromagnetic Model}

The model geometry of the conceptual machine used for the coil topology optimization is shown on Fig. 2. The 16 pole machine is non-salient and can be analysed with an air-gap armature winding or a slotted armature winding (simplified with the Carter coefficient). The FE model is reduced to one pole section 
using electromagnetic periodicity. The magnetic fields are calculated in steady state using the vector potential formulation of Maxwell's equations. The ferromagnetic steel used in the model for both cold and room temperature magnetic parts is the silicon steel M800-50.

The optimization space domain corresponds to the six double pancake coils. Each double pancake coil was presented with one rectangle of width of $10 \mathrm{~mm}$.

\section{Coil Magnetic Anisotropy}

An important feature of HTS machines, which needs to be taken in to account, is the high sensitivity of the HTS current carrying capacity in magnetic fields. The prevailing impact on the critical current of the HTS tapes is the perpendicular direction of the magnetic flux to the wide side of the HTS tape. In the machine a single HTS tape is not in a homogenous field but rather, the gradients of the magnetic field can be very large over the entire HTS coil. However, critical currents of HTS tapes are usually derived by the 'short piece' experiment in different fields and field directions, where the field in the experiment is homogenous.

In the model, the perpendicular component of the flux density $\hat{B}_{\perp}^{[p, j]}(x)$ for tape $p$, is averaged over tape $p$ width, $w_{\text {tape }}$, as shown in (1).

$$
\hat{B}_{\perp}^{[p, j]}(x)=\frac{1}{w_{\text {tape }}} \int_{0}^{w_{\text {tape }}}{ }^{j} \text { opt } \cdot\left|B_{\perp}(x, y)\right| d y
$$

The ${ }^{j}$ opt represents the optimization variable which corresponds to the one type of HTS and $\left|B_{\perp}(x, y)\right|$ is the absolute value of the perpendicular component of the magnetic flux density. The peak perpendicular flux density, $B_{\max \perp}^{j}$, experienced by coils made from the $j$ HTS material, can be found by searching for a maximum of the perpendicular flux density experienced by each tape calculated in (1), over the entire optimization domain $\Omega_{\text {coils }}$, like in (2).

$$
B_{\max \perp}^{j}=\stackrel{\Omega_{\text {cooils }}}{M A X}\left(\hat{B}_{\perp}^{[p, j]}(x)\right)
$$

At this point we need to consider the excitation strategy. The conventional excitation strategy for a synchronous machine implies one excitation system and one excitation current. Yet it might be wise to allow more excitation currents in the case of HTS machines, assuming that the complication in the excitation system does not cancel out potential savings in HTS material. In this model that feature is investigated and compared with the case of having only one current supply.

The total spatial current distribution $J(x, y)$ with more than one excitation current supply, is calculated as the sum of all the coil current density contributions, as shown in the (3). The $J_{c j}$ is the critical current density for the $j$ type of HTS tape where the ${ }^{j} \operatorname{opt}(x, y)$ is the optimization variable which controls the spatial distribution of the $j$ type HTS in the coil domain. An additional scalar variable is tied to each HTS type, $K_{j}$, scaling current density of that coil from the value defined by the critical current density $J_{c}(B)$

$$
J(x, y)=\sum_{j}{ }^{j} \operatorname{opt}(x, y) \cdot K_{j} \cdot J_{c j}\left(B_{\max \perp}^{j}\right)
$$

The $K_{j}$ coefficient is assumed to be fixed to 0.8 in the case of single HTS type employed, thus making sure the electrical loading of the HTS is $80 \%$ of the critical loading. In the case of different HTS types, the $K_{j}$ should also be an optimization variable with values bounded between 0.4 and 0.8 .

If one excitation current is allowed, (4) defines the maximal safe supply current.

$$
I_{\text {field }}=\operatorname{MIN}_{j}\left(K_{j} \cdot J_{c j}\left(B_{\max \perp}^{j}\right) \cdot{ }^{j} A_{\text {tape }}\right)
$$

Since the different tapes have different cross sections ${ }^{j} A_{\text {tape }}$, the engineering current densities need to be scaled in order to correspond to $I_{\text {field }}$. The total spatial distribution of the coil domain in this case is formulated in (5).

$$
J(x, y)=\sum_{j}^{j} \text { opt }(x, y) \cdot \frac{I_{\text {field }}}{j_{\text {tape }}}
$$

\section{E. Optimization Formulation}

Topology optimization is used in structural studies to ensure minimum material usage and cost, and increased robustness of the structure, especially in an application where over sizing caries high cost penalty (airplane industry) [10].

The objective function, which in COMSOL [11] implementation is minimized by default, will have several terms in the formulation of the optimization problem. The form of the generalized objective function, which is minimized is shown in (6).

$$
\min \text { Objectiv }=\sum_{k=1}^{3} o b j_{k}
$$

where $o b j_{k}$ are contributions to the objective function.

The optimization variables, ${ }^{j}$ opt $(x, y)$, are defined in the 2D space which corresponds to the space intended for the HTS coils. The idea is to allow the optimization algorithm to control the spatial distribution of the HTS tapes. All optimization variables are constrained between zero and one with (7) and (8).

$$
\begin{aligned}
0 \leq{ }^{j} \operatorname{opt}(x, y) & \leq 1 \\
\sum_{j}{ }^{j} \operatorname{opt}(x, y) & \leq 1
\end{aligned}
$$

If the optimization variable is one, current carrying HTS will be present at those coordinates and if it is zero, no HTS tape will be present. Additionally the sum of all the optimization variables at a specific coordinate need to be less than or equal to one, which corresponds to the statement that the same space can have only one tape.

However, since it is not possible to constrain the optimization variables in COMSOL to only binary values, the first term of the objective function, $o b j_{1}$, needs to penalize all values between zero and one, which is done with (9).

$$
o b j_{1}=\sum_{j}\left(c_{o b j 1} \int_{\Omega_{c o i l s}}\left[a_{o b j 1}-\left({ }^{j} o p t-b_{o b j 1}\right)^{2}\right] d \Omega_{c o i l s}\right)
$$


where the adjusting constants $a_{o b j 1}, b_{o b j 1}$ and $c_{o b j 1}$ are set to $0.25,0.5$ and 100 respectively, in order to allow this term to have significant effect to the value of the objective function.

$o b j_{2}=\left(a_{o b j 2}(B_{r, \text { peak }}^{\text {design }}-\underbrace{2 \int_{-\pi / 2}^{\pi / 2} B_{r} \cos (\theta) d \theta_{\text {armature }}}_{\text {firstharmonic }})\right)^{2}$

The second term of the objective function, $o b j_{2}$, shown in (10) is to make sure that the fundamental harmonic of the radial air-gap flux density, $B_{r}$, is maintained closely to the desired design value, $B_{r, \text { peak }}^{\text {design }}$. Thus, the $o b j 2$ will have the dominating effect on the objective function as long as the air-gap flux is far from the desired value. The constant $a_{o b j 2}$ controls how dominant this term is in the final objective function and in this implementation its value is set to 5 .

The final term of the objective function is the price contributions of each HTS which is calculated using (11).

$$
o b j_{3}=\sum_{j}\left(\int_{\Omega_{\text {coil }}}{ }^{j} \text { opt } \cdot \frac{C_{j}}{j^{j} A_{\text {tape }}} \cdot d \Omega_{\text {coil }}\right)
$$

where the price of each tape is $C_{j}$.

\section{RESULTS}

In order to compare the coil optimization results of the generator design shown in the Fig. 2, the price of the optimized coil topology made from a single type of HTS material (both $1 \mathrm{G}$ and $2 \mathrm{G}$ ) is compared.

The limiting factor during simulations, especially for the case of multiple tape coils, was a built-in optimization algorithm in COMSOL, which searches only for local minimum [10]. Thus it is very important to keep in mind that the solution, which is a local minimum is highly dependent on the initial conditions. This requires a good initial estimate of which tape should be in which portion of the coil.

1) Single Tape Coils: An optimization example is done on the 16 pole air-gap stator machine. For the machine design input the flux density was set to $3 \mathrm{~T}$ with an HTS operating temperature of $20 \mathrm{~K}$.

The optimization results for the 16 pole machine in Fig. 2 are shown in Fig. 4. In the case where the coils consist of a single HTS, the coils made from 2 G 120 A tape (with a relative price of $3 \mathrm{pu}$ ), had a price of $54 \times 10^{3} \mathrm{pu}$, as compared to the coils made from $1 \mathrm{G} 180 \mathrm{~A}$ tape (with a relative price of $2 \mathrm{pu}$ ) where the price was only $18 \times 10^{3} \mathrm{pu}$. The price difference between 1 $\mathrm{G}$ and $2 \mathrm{G}$ is a factor of three which is in line with expectations, since $1 \mathrm{G}$ tapes have more current capacity between $2 \mathrm{~T}$ and $3 \mathrm{~T}$ and are 50\% cheaper, according to Fig. 3. The coils from ultra thin $2 \mathrm{G} 140$ A tape would result in a price of $63 \times 10^{3} \mathrm{pu}$. However, the cost impact of the coil space reduction is not taken into account here. This could have a significant impact on the overall price of the machine as it could result in a reduced effective air-gap and hence a lower required value of ampere-turns

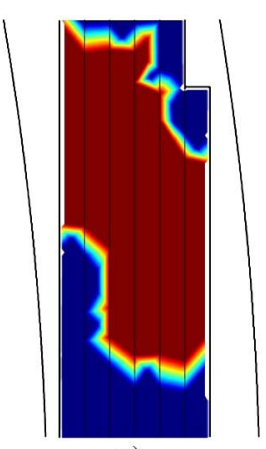

a)

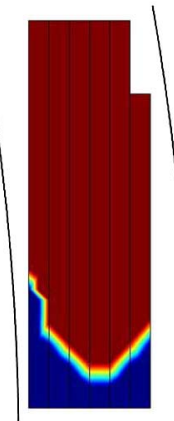

b)

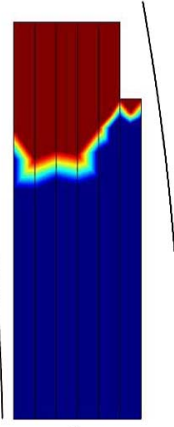

c)
Fig. 4. Optimization results for HTS coils with single HTS type at $20 \mathrm{~K}$. The results are shown only for the upper side of the coils, since the current distribution is symmetrical to the $\mathrm{x}$ axis. The dark red is the HTS active domain and the dark blue empty space. (a) 1G-180A-2pu; (b) 2G-120A-3pu; (c) 2G-140A-4pu.

for a given air-gap fluxes density. The lowest grading $1 \mathrm{G} 100$ $\mathrm{A}$ and $2 \mathrm{G} 80 \mathrm{~A}$ tapes were unable to produce the required $3 \mathrm{~T}$ with the allowed coil space.

The optimization results show that the $1 \mathrm{G}-180 \mathrm{~A}$ tape is most advantageous at $20 \mathrm{~K}$. It has the lowest price and degree of magnetic anisotropy. The results for the ultrathin 2 G-140 A tape are interesting, with a very compact coil of similar price to the 2 G-120 A tape. This tape requires further analysis which allows for the potential benefits of the compact coil to be taken into account.

2) Multiple Excitation Currents: In order to investigate the potential savings in HTS material by allowing multiple excitation currents, we have examined the extreme case were each tape has its own current supply, which should yield the lowest amount of HTS needed to achieve $3 \mathrm{~T}$. This means that each tape operates with its own maximal safe $J$ defined by $J_{c}(B)$. It is not realistic that each tape would have its own current supply, but it is realistic to imagine that the HTS area was divided into sections with a few separate current supplies.

The optimization was carried out with the same tapes as in the single excitation current case. The optimization resulted in the following price for $1 \mathrm{G}-180 \mathrm{~A}, 2 \mathrm{G}-120 \mathrm{~A}$ and $2 \mathrm{G}-140 \mathrm{~A}$ respectively: $12 \times 10^{3} \mathrm{pu}, 25 \times 10^{3} \mathrm{pu}$ and $26 \times 10^{3} \mathrm{pu}$.

The optimization has confirmed the potential for significant HTS savings if multiple current supplies are allowed. The tapes with higher degree of nonlinearity in $J_{c}-B$, as $2 \mathrm{G}$ at $20 \mathrm{~K}$, have potential savings exceeding $50 \%$. Such savings are less for the $1 \mathrm{G}$ tapes and are in the order of $30 \%$ at $20 \mathrm{~K}$.

\section{CONCLUSION}

In this article an optimization algorithm for HTS coils in electrical machines is presented. We have estimated the price ratios of three commercially available types of HTS and used it to derive the price ratios for excitation coils of multi-pole HTS machines. The results were clearly in favor of $1 \mathrm{G}$ tape at $20 \mathrm{~K}$, due to its lower cost and higher current capacity. Promising results were achieved with ultra thin $2 \mathrm{G}$ tape, which require further investigation. Additionally, the article discusses the potential HTS savings of using multiple excitation supplies. Future work will focus on optimal design of coils with two and more types of tapes with one or more current supplies. 


\section{REFERENCES}

[1] M. H. Ali, W. Bin, and R. A. Dougal, "An overview of SMES applications in power and energy systems," IEEE Trans. Sustainable Energy, vol. 1-1, pp. 38-47, Mar. 18, 2010.

[2] J. Cho et al., "Design and experimental results of a 3 phase $30 \mathrm{~m}$ HTS power cable," IEEE Trans. Applied Superconductivity, vol. 16, no. 2, pp. 1602-1605, June 2006.

[3] S. S. Klasi, "Advances in synchronous machines employing high temperature superconductors (HTS)," in IEEE Int. Conf. Electric Machines and Drives Conference 2003-IEMDC'03, vol. 1, pp. 24-28.

[4] G. Klaus, "Design challenges and benefits of HTS synchronous machines," in IEEE General Meeting 2007, June 2007, pp. 1-8.
[5] P. J. Masson and C. A. Luongo, "HTS machines for applications in all-electric aircraft," in IEEE General Meeting 2007, June 2007, pp. $1-6$.

[6] E. J. Davies, “Airgap winding for large turbogenerators," in Proc. of the Institution of Electrical Engineers, 1971, vol. 118-3.4, pp. 529-535.

[7] [Online]. Available: http://www.superpower-inc.com/content/technical-documents

[8] [Online]. Available: http://global-sei.com/super/hts_e/index.html

[9] [Online]. Available: http://www.amsc.com/products/htswire/

[10] M. P. Bendsøe, N. Olhoff, and O. Sigmund, "Recent developments in the commercial implementation of topology optimization," in IUTAM Symp. on Topological Design Optimization of Structures, Machines and Materials, 2006, vol. 137, pp. 239-248.

[11] "Comsol Multiphysic 4.0a-Optimization Module, Software Manual," 2010. 